\title{
Spontaneous breathing test conducted with and without automatic tube compensation does not differ from a metabolic standpoint
}

\author{
AF Lago ${ }^{1 *}$, EC Gonçalves ${ }^{1}$, EC Silva ${ }^{1}$, MG Menegueti ${ }^{1}$, EA Nicolini ${ }^{1}$, M Auxiliadora-Martins ${ }^{1}$, AC Gastaldi ${ }^{2}$, \\ A Basile-Filho ${ }^{1}$
}

From ESICM LIVES 2015

Berlin, Germany. 3-7 October 2015

\section{Introduction}

Weaning from mechanical ventilation is defined as the process of release of ventilatory support and how the evaluation of this phase is conducted in the Spontaneous Breathing Test (SBT). One of the most used modes of SBT is the Continuous Positive Airway Pressure (CPAP). However, together with the mechanical ventilation modes it can be used the Automatic Tube Compensation (ATC), which compensates the resistance imposed by the endotracheal tube.

\section{Objectives}

The main goal of this study was to compare the Oxygen Consumption $\left(\mathrm{VO}_{2}\right)$, Carbon Dioxide Production
$\left(\mathrm{VCO}_{2}\right)$ and Energy Expenditure (EE) by Indirect Calorimetry (IC) during the SBT in CPAP with and without ATC.

\section{Methods}

The study was a prospective randomized, controlled crossover trial that enrolled 40 patients admitted to the Intensive Care Unit of a University Hospital. Participants were randomly allocated in Group 1, in which it was started the SBT in CPAP with ATC and later in CPAP without ATC, or in Group 2, which was started the SBT in CPAP without ATC and then CPAP with ATC.

Table 1

\begin{tabular}{|c|c|c|c|}
\hline VARIABLES & $\begin{array}{l}\text { ESTIMATED DIFFERENCES BETWEEN THE ATC } \\
\text { AND WITHOUT ATC }\end{array}$ & $\begin{array}{c}p \\
\text { VALUE }\end{array}$ & $\begin{array}{l}\text { 95\% CONFIDENCE } \\
\text { INTERVAL }\end{array}$ \\
\hline VO2 (Oxygen Consumption) (mL/kg.min-') & -1.6 & 0.23 & {$[-4.36 ; 1.07]$} \\
\hline EE (Energy Expenditure) (kcal/day-1 $\left.{ }^{1}\right)$ & -5.4 & 0.500 & {$[-21.67 ; 10.79]$} \\
\hline VCO2 (Carbon Dioxide Production) (mL/kg.min-1) & 0.3 & 0.82 & {$[-2.49 ; 3.11]$} \\
\hline RQ (Respiratory Quotient) & 0.0004 & 0.63 & {$[-0.01 ; 0.02]$} \\
\hline Peak pressure (cm H20) & 2.00 & 0.0001 & {$[1.39 ; 2.62]$} \\
\hline Tidal volume $(\mathrm{mL})$ & 13.32 & 0.5415 & {$[-30.65 ; 57.30]$} \\
\hline Respiratory rate (bpm) & 0.34 & 0.5688 & {$[-0.87 ; 1.56]$} \\
\hline $\begin{array}{l}\text { P0.1 -Airway occlusion pressure } 100 \text { milliseconds after onset of } \\
\text { inspiratory flow }(\mathrm{cm} \mathrm{H} 2 \mathrm{O})\end{array}$ & -0.49 & 0.0073 & {$[-0.84 ;-0.14]$} \\
\hline
\end{tabular}

\footnotetext{
${ }^{1}$ Ribeirão Preto Medical School, University of São Paulo, Department of Surgery and Anatomy, Ribeirão Preto, Brazil
}

(c) 2015 Lago et al.; This is an Open Access article distributed under the terms of the Creative Commons Attribution License (http:// creativecommons.org/licenses/by/4.0), which permits unrestricted use, distribution, and reproduction in any medium, provided the original work is properly cited. 


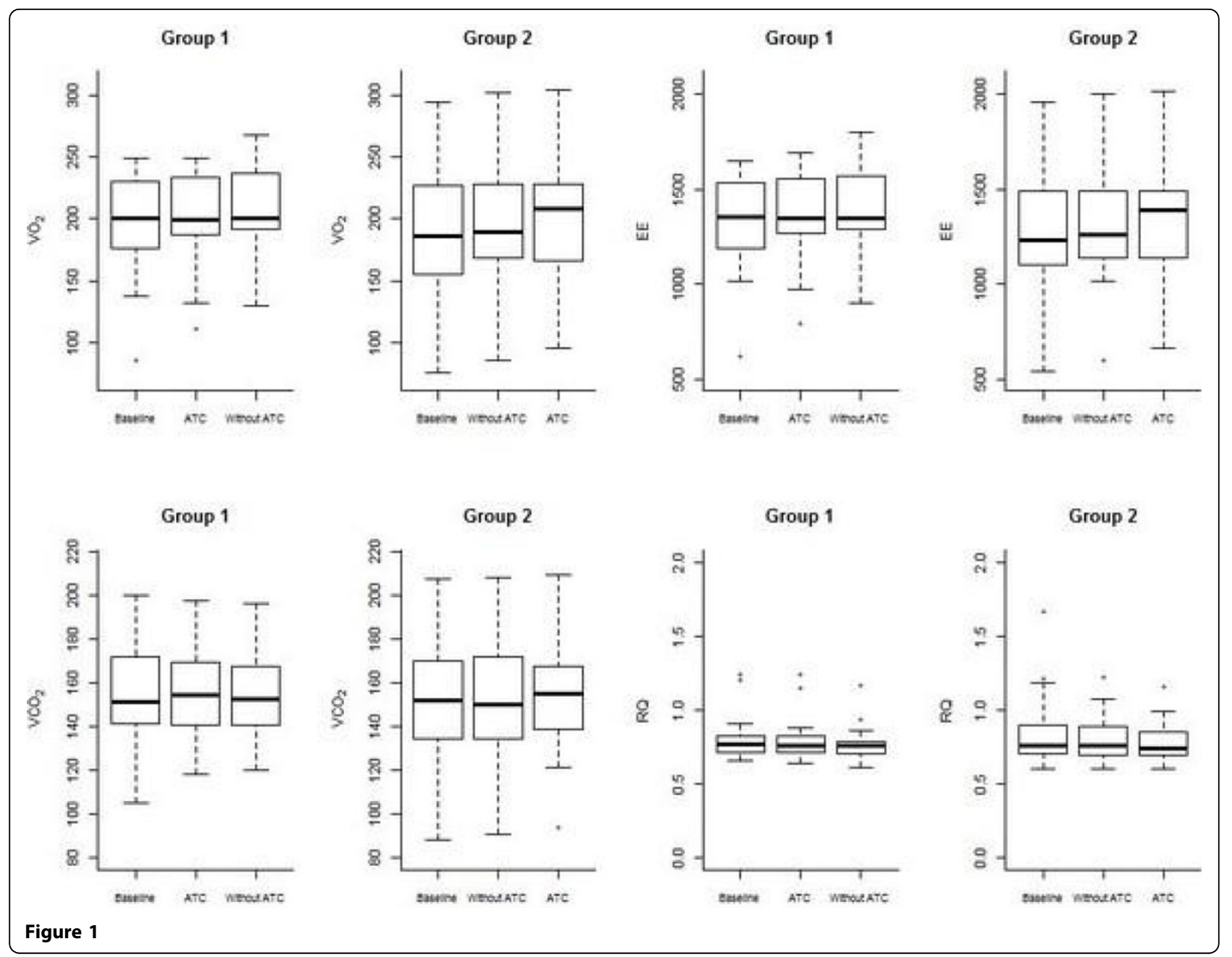

\section{Results}

Table 1 and graph 1 summarize the differences between the treatments ATC and without ATC concerning metabolic and respiratory variables.

\section{Conclusions}

There were no metabolic differences evidenced by indirect calorimetry for $\mathrm{VO}_{2}, \mathrm{EE}$ and $\mathrm{VCO}_{2}$ during the SBT with and without ATC.

\section{Authors' details}

'Ribeirão Preto Medical School, University of São Paulo, Department of Surgery and Anatomy, Ribeirão Preto, Brazil. 'Ribeirão Preto Medical School, University of São Paulo, Physiotherapy Department, Ribeirão Preto, Brazil.

\section{Published: 1 October 2015}

\section{Reference}

1. Dos Santos LJ, Hoff FC, Condessa RL, Kaufmann ML, Vieira SR: Energy expenditure during weaning from mechanical ventilation: Is there any difference between pressure support and T-tube? I Crit Care 2011, 26:34-41.
doi:10.1186/2197-425X-3-S1-A668

Cite this article as: Lago et al:: Spontaneous breathing test conducted with and without automatic tube compensation does not differ from a metabolic standpoint. Intensive Care Medicine Experimental 2015 3(Suppl 1): A668.

\section{Submit your manuscript to a SpringerOpen ${ }^{\circ}$ journal and benefit from:}

- Convenient online submission

- Rigorous peer review

- Immediate publication on acceptance

- Open access: articles freely available online

- High visibility within the field

- Retaining the copyright to your article

Submit your next manuscript at $\boldsymbol{s p r i n g e r o p e n . c o m ~}$ 